\title{
Atividade antimicrobiana de extratos de raízes de Byrsonima crassifolia
}

\section{Antimicrobial activity of extracts of Byrsonima crassifolia roots}

\author{
Luís Fernando Albarello GELLEN ${ }^{[1, *]}$ (iD) e Edgard Henrique Costa SILVA ${ }^{[2]}$ (D)
}

[1] Docente do Centro Universitário Luterano de Palmas, Centro de Ciências da Saúde. Avenida Teotônio Segurado 1501, Região Sul, CEP. 77019900. Palmas, TO, Brasil.

[2] Discente do Programa de Mestrado em Agronomia (Produção Vegetal) da Universidade Estadual Paulista, Faculdade de Ciências Agrárias e Veterinárias-Campus de Jaboticabal. Departamento de Produção Vegetal, Via de Acesso Prof. Paulo Donato Castellane, s/n, CEP 14884-900, Jaboticabal, SP, Brasil. edgarddragde@gmail.com

* Autor para correspondência: gellenbiomedico@hotmail.com INFORMAÇÃO

Recebido em: 15/12/2015

Aceito em: $21 / 05 / 2016$

Publicado em: 29/06/2016

Document Object Identifier $10.18067 / \mathrm{jbfs} . v 3 \mathrm{i} 2.88$

Crossref

Editor:

Victor Hugo G. Sales

jbfs@ifap.edu.br

ID JBFS0882015

Avaliação a cega por pares

Prot. 0882016R01

Prot. 0882016R02

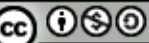

EY NC SA JBFS all rights

Copyright: (C) 2016

\section{RESUMO}

A Byrsonima crassifolia popularmente conhecida como "murici", é amplamente difundida nas regiões norte, nordeste e centro-oeste por ser bastante utilizada na culinária local, tanto pelo seu gosto exótico, quanto pelos seus efeitos terapêuticos. $O$ objetivo do trabalho foi avaliar o potencial antimicrobiano do extrato de raízes de $B$. crassifolia sobre bactérias de interesse médico. As amostras de $B$. crassifolia foram coletadas no interior do Estado do Tocantins, em seguida encaminhadas para o Centro Universitário Luterano de Palmas - TO, onde foram realizados os processos de produção dos extratos provenientes das raízes. Os demais procedimentos foram realizados na Universidade Federal do Tocantins, campus de Gurupi. Foram utilizadas quatro cepas bacterianas, sendo elas: Klebsiella pneumoniae, Escherichia coli, Staphylococcus aureus e Pseudomonas aeruginosa. A concentração dos extratos consistiu de $10 \%$ aquecido, $20 \%$ aquecido e $20 \%$ não aquecido, verificados em teste de disco-difusão, cujas avaliações procederam-se 24 horas após aplicação do extrato, o resultado sendo expresso em $\mathrm{mm}$. As concentrações do extrato aquoso de $B$. crassifolia foram eficientes na inibição bacteriana, exceto para $E$. coli. Foram observadas nas raízes pigmentações de cor característica de antocianina e quercetina, condição que pode ter influenciado no potencial antimicrobiano, pela ação antibacteriana destes dois flavonoides natural. .

Palavras-chave: Byrsonima crassifolia, antibacteriano, sensibilidade, raízes

ABSTRACT -The Byrsonima crassifolia popularly known as "murici" is widespread in the North, Northeast and Midwest. Widely used in local cuisine, both for its exotic taste as for its therapeutic effects. The objective was to evaluate the antimicrobial potential of B. crassifolia root extract on bacteria of medical interest. Samples of B. crassifolia were collected within the State of Tocantins, then forwarded to the Centro Universitário Luterano de Palmas - TO, where extracts of production processes from the roots were performed. The other procedures were carried out at the Universidade Federal do Tocantins, Gurupi campus. Four bacterial strains were used, as follows: Klebsiella pneumoniae, Escherichia coli, Staphylococcus aureus and Pseudomonas aeruginosa. The concentration of the extracts consisted of warm 10\%, 20\%, 20\% heated and unheated tested in disk diffusion test, which is carried ratings 24 hours after application of the extract, the result is expressed in $\mathrm{mm}$. The concentration of the aqueous extract of B. crassifolia were effective in inhibiting bacterial, except for $E$. coli. They were observed in color pigmentations roots characteristic of anthocyanin and quercetin, a condition that may have influenced the antimicrobial potential, the antibacterial action of these two natural flavonoids.

Keywords: Byrsonima crassifolia, antibacterial, sensitivity, roots

Financiamento: Os autores reportam que não houve suporte e auxílio financeiro.

Conflito de interesse: Os autores declaram que não há conflito de interesse.

Como citar esse documento (ABNT):

GELLEN, L.F.A.; SILVA, E.H.C. Atividade antimicrobiana de extratos de raízes de Byrsonima crassifólia. Journal of Bioenergy and Food Science, v.3, n.1, p.63-71, 2016. DOI:10.18067/jbfs.v3i2.88 


\section{INTRODUÇÃO}

O Brasil é o quinto país do mundo em extensão territorial, abrigando uma enorme biodiversidade. O bioma Cerrado representa cerca de $20 \%$ desta área continental, ou seja, contabilizando as áreas periféricas em domínios de transição, abrange cerca de dois milhões de quilômetros quadrados. ${ }^{1}$

Encontra-se na literatura descrição de cerca de 6.253 espécies de plantas nativas e distribuídas em 160 famílias na região do cerrado brasileiro. ${ }^{2-4}$

Segundo a Organização Mundial da Saúde, ${ }^{5}$ cerca de $80 \%$ da população mundial faz uso de tratamentos sugeridos pela medicina natural ou, como também é conhecida, medicina tradicional. ${ }^{1} \mathrm{O}$ uso de plantas no tratamento de doenças tem tradição milenar. Portanto, o efeito benéfico gerado por esse uso medicinal das plantas vem despertando interesse junto aos pesquisadores há muito tempo. Um grande número de plantas permanece desconhecido tanto do ponto de vista medicinal quanto do ponto de vista químico e farmacológico. ${ }^{6,7}$

$\mathrm{Na}$ atualidade, um dos grandes problemas enfrentados pela ciência médica está no aumento dos processos de resistência de microrganismos de interesse médico a fármacos disponíveis no mercado, como é o caso de algumas cepas de Salmonella spp., Shigella spp. e Estreptococcus spp. ${ }^{3,8,9}$

Crescentes casos de resistência a antimicrobianos não estão ocorrendo em focos isolados no planeta. Esse problema tem se tornado um caso de saúde pública internacional. Essas reações de resistência microbiana se dão pelo uso inadequado de antimicrobianos pela população, sem o controle ou consulta prévia aos profissionais da saúde qualificados. ${ }^{7,8}$ Desse modo, o fenômeno da resistência microbiana exige $o$ uso de antimicrobianos mais potentes ou ainda o uso de dois ou mais medicamentos para o combate de tais bactérias. Estes problemas geram altos custos para o sistema de saúde pelo uso de antibióticos mais fortes e caros, o que acarreta custos extras para obtenção destes. ${ }^{7,10}$

Várias plantas de uso popular para fins terapêuticos tiveram sua eficácia comprovada a partir de resultados obtidos por conhecimento empírico, ou seja, ao ter uma relação entre a patologia para a qual era indicada e o fato de possuir forte concentração de radicais livres como agente etiológico. ${ }^{11}$ Plantas como a sucupira (Pterodon emarginatus), que possuem em seu extrato bruto um potencial fungicida e bactericida, apresentam-se como uma alternativa econômica e ecológica, pois o processo de obtenção do extrato faz o uso apenas dos seus frutos, assim sem comprometer o estado físico das árvores. ${ }^{12}$

Segundo Pimentel ${ }^{13}$ e Moreno, ${ }^{14}$ as pesquisas envolvendo plantas medicinais são complexas e apresentam um caráter multidisciplinar, principalmente quando o objetivo da pesquisa é encontrar substâncias ativas e úteis para a área terapêutica.

Várias plantas nativas do Cerrado, pertencentes a diferentes famílias, estão sendo empregadas pela população na região norte do Brasil, seja para fins alimentícios ou terapêuticos, sendo que essas práticas se intensificam na localização da região do cerrado brasileiro. ${ }^{11}$

Essas plantas são usadas para tratamento de várias doenças e, como exemplo, podem-se citar as plantas da família Malpighiaceae, que compreendem aproximadamente 60 gêneros e 1200 espécies, sendo encontradas no Brasil cerca de $50 \%$ dessas espécies. Os gêneros mais importantes na América Meridional são Malpighia e Byrsonima. ${ }^{15,16}$

O murici (Byrsonima crassifolia (L.) Rich) como é conhecido popularmente, pertence ao gênero Byrsonima, é nativo do Norte, Nordeste e da região central do Brasil, podendo ser encontrado em alguns locais serranos da região Sudeste. Suas características são de plantas arbóreas, com galhos retorcidos e de porte médio, tendo altura entre três e cinco metros, com flores em forma de cachos que medem entre 15 e $20 \mathrm{~cm}$, e seus frutos amarelados quando maduros são menores que uma moeda. ${ }^{16} \mathrm{E}$ bastante apreciado por seu sabor, sendo conhecido como "murici branco", "murici amarelo"," murici vermelho"," murici da chapada"," murici do brejo", "murici da mata", dentre outros nomes. ${ }^{17}$

Espécies de Byrsonima, como a Byrsonima crassa Niedenzu, conhecida como murici vermelho ou murici do cerrado, têm suas folhas e cascas usadas pela população em disfunções gástricas, infecções cutâneas, agente antiofídico e ainda como anti-diarréico. ${ }^{15,17,18}$ A Byrsonima coccolobifolia possui ação molusquicida contra Biomphalaria 
glabrata e bactericida para Staphylococcus aureus, Bacillus cereus e Pseudomonas aeruginosa. ${ }^{7}$

Na medicina popular, há relatos do uso dos frutos e folhas do murici do cerrado (B. crassifolia) em tratamentos de patologias relacionadas ao trato gastrointestinal, como úlceras causadas por ação bacteriana, diarreias e infecções. Suas raízes são usadas como cicatrizante de feridas, infecções da boca e da garganta, como gengivites, amigdalites e faringites. Há também relatos do uso das raízes para tratamento de corrimento vaginal. ${ }^{19}$

O presente trabalho teve como objetivo avaliar o potencial antimicrobiano do extrato de raízes de Byrsonima crassifolia frente a bactérias de interesse médico

\section{MATERIAL E MÉTODOS}

\section{A) Local de Coleta e Realização}

As amostras de $B$. crassifolia foram coletadas no estado do Tocantins, na região do município de Cristalândia. As raízes foram extraídas por processo de escavação, com a retirada da planta do solo e consequente corte das raízes. Em seguida, as raízes foram encaminhadas para o Centro Universitário Luterano de Palmas - TO, onde foram realizados os processos de produção dos extratos provenientes das raízes.

\section{B) Produção dos extratos}

O procedimento consistiu primeiramente na lavagem das raízes em água corrente. Em seguida, elas foram secas e submetidas a secagem em estufa com circulação de ar forçada, com temperatura e umidade $\left(37^{\circ} \mathrm{C} / 10 \%\right)$ controladas a cada 24 horas.

Com a desidratação concluída, utilizou-se a metodologia descrita por Simões et al., ${ }^{20}$ com modificações, para obtenção do material particulado. As raízes foram tamisadas em moinho de facas, aumentando assim a superfície de contato do soluto (raízes) com o solvente (no caso deste trabalho, água). Esse processo de tamisação repetiu-se por duas etapas para obtenção de partículas mais homogêneas e menores.

Posteriormente, as raízes foram submersas em água destilada, vedadas e protegidas da luz, sendo mantidas em agitador magnético por vinte e quatro horas. Após esse período de agitação, a solução foi submetida ao processo de centrifugação a 4500 rpm para separação da massa de raízes do extrato bruto. O precipitado foi descartado e o sobrenadante utilizado. Os extratos foram produzidos nas concentrações de $10 \%$ não aquecido e $20 \%$ aquecido $(50$-C) e não aquecido. Quando o extrato a $10 \%$ não apresentou atividade antimicrobiana, aqueceu-se a 50 으, sendo concentrado para $20 \%$. Utilizou-se o aquecimento para identificar a existência de bioativos termorresistentes e com atividade antimicrobiana; como função secundária o aquecimento pode degradar biomoléculas que interferem na atividade antimicrobiana.

\section{C) Preparação da Escala de McFarland}

A solução de McFarland é utilizada como padrão de concentração estimada de bactérias em Unidades Formadoras de Colônia (UFC). Fez-se a comparação da turbidez da solução de McFarland com a turbidez de solução isotônica de $\mathrm{NaCl}$ a $0,9 \%$ com determinada quantidade de bactérias.

Tendo como base a turbidez da escala de McFarland, estimou-se e controlou-se a quantidade relativa de bactérias contidas na suspensão, padronizando assim a quantidade de cepas contidas no Agar nutritivo e sem haver possíveis resultados falsos negativos por uma concentração elevada de microrganismos no teste. ${ }^{21}$

Para preparação da solução equivalente a $1,5 \times 10^{8}$ UFC, utilizou-se $0,5 \mathrm{~mL}$ de $\mathrm{BaCl}_{2} 0,048$ mol.L${ }_{1}^{1}$ para $99,5 \mathrm{~mL}$ de $\mathrm{H}_{2} \mathrm{SO}_{4} 0,18$ mol.L-1 . A absorbância foi medida em um espectrofotômetro com via de luz de $1 \mathrm{~cm}$ e cubeta correspondente para determinar absorbância a $625 \mathrm{~nm}$. Quando a solução emitir uma absorbância de 0,008 nm, o valor condiz com a turbidez de uma solução salina contendo $1,5 \times 10^{8}$ UFC. $\mathrm{mL}^{-1}{ }^{21}$

\section{D) Produção dos discos de antibiograma com os extratos}

Os discos com extratos da raiz de Byrsonima crassifolia foram produzidos com papel de filtro, sendo os extratos adicionados aos discos para absorção dos princípios ativos extraídos das raízes, que foram colocados para secagem em estufa à temperatura de $37^{\circ} \mathrm{C}$. Alguns discos foram produzidos com extratos concentrados para $20 \%$ por aquecimento a $50 \circ \mathrm{C}$. Outros discos foram produzidos com extratos sem aquecimento nas concentrações de $10 \%$ e $20 \% .^{22,23}$

As cepas padrão das bactérias em foco foram as de Klebsiella pneumoniae (ATCC700603), 
Escherichia coli (ATCC 35218), Staphylococcus aureus (ATCC 25923) e Pseudomonas aeruginosa (ATCC 27853). Estas cepas foram semeadas em meio Agar Brain Heart Infusion (Agar BHI), incubadas em estufa a $37 \circ \mathrm{C}$, repicadas novamente no meio Agar $\mathrm{BHI}$ após 24 horas. O processo foi repetido por três vezes para fortalecer as cepas bacterianas, evitando assim resultados falsos positivos. Por último, as cepas foram semeadas em Agar Mueller Hinton para realização do antibiograma com os discos de extrato das raízes de $B$. crassifolia.

e) Teste Disco-Difusão
Os testes de sensibilidade obedeceram aos protocolos do NCCLSI sobre diluições com cepas padrão de bactérias anaeróbias e aeróbias M-7 e M11, e $M-6$, este último contendo menção para uso do Agar Muller Hilton para testes de disco-difusão (NCCLS).

O antibiograma foi realizado em Agar Mueller Hinton e a padronização da concentração de bactérias feita pela escala de MacFarland. Os antibióticos utilizados foram Penicilina, Meropenem e Amoxicilina + Ácido Clavulânico (Tabela 1).

Tabela 1: Controles positivos para cada cepa padrão determinadas pelo Clinical and Laboratory Standards Institute (CLSI).

Table 1. Positive controls for each standard strain determined by the Clinical and Laboratory Standards Institute (CLSI)

\begin{tabular}{lc}
\hline Cepas Padrão & Controles Positivos de Sensibilidade \\
\hline Staphylococcus aureus ATCC 25923 & Penicilina \\
Klebsiella pneumoniae ATCC700603 & Meropenen \\
Pseudomonas aeruginosa ATCC 27853 & Meropenen \\
Escherichia coli ATCC 35218 & Amoxicilina + Ácido Clavulânico \\
\hline
\end{tabular}

As placas foram incubadas em estufa a $37^{\circ} \mathrm{C}$ por 24 horas. Os discos de antibióticos serviram como controle positivo do antibiograma e os discos confeccionados sem extrato como controles negativos (Figura 1 ).

Os insumos para preparação dos meios utilizados foram $200 \mathrm{~mL}$ de Agar BHI para revitalização de cada cepa bacteriana para posterior teste antimicrobiano, no qual fora utilizado cerca de $2000 \mathrm{~mL}$ de Agar Muller Hilton para cada cepa bacteriana. Ao todo foram 30 placas para cada bactéria, totalizando 10 repetições para cada concentração e tipo de obtenção do extrato.

Após coletados os dados, esses foram submetidos à análise de variância, e as médias foram comparadas pelo teste de Tukey à $5 \%$ de probabilidade, com o auxílio do programa estatístico AgroEstat. ${ }^{24}$ Os dados foram transformados para $\sqrt{ } \mathrm{x}+1$.

\section{RESULTADOS E DISCUSSÃO}

Apresentam-se na Tabela 2 os resultados dos testes com raízes de Byrsonima crassifolia nas diferentes concentrações, para a inibição das cepas de Klebsiella pneumoniae, Staphylococcus aureus e Pseudomonas aeruginosa.

Observou-se inibição do crescimento das cepas de Klebsiella pneumoniae, Pseudomonas aeruginosa e Staphylococcus aureus na concentração de $10 \%$ de extrato não aquecido. No entanto, essa mesma concentração não proporcionou atividade antimicrobiana para a cepa de Escherichia coli. Todos os controles positivos confirmaram o seu grau de inibição de acordo com os parâmetros estabelecidos e correspondentes aos comportamentos das cepas ATCC utilizadas, dados descritos no manual NCCLS. ${ }^{25}$ Contudo, o controle positivo para Escherichia coli, Amoxilina + Ácido Clavulânico não evidenciou nenhum efeito inibitório, sendo sua medida de halo para sensibilidade acima ou igual a $18 \mathrm{~mm},{ }^{25}$ tornando necessário um reteste com alteração do controle positivo.

O segundo antibiótico eletivo para esta cepa ATCC é o Meropenen, cujos resultados do controle positivo foram fiéis aos dados fornecidos pelo $\mathrm{NCCLS}^{25}$, no qual o padrão dos halos é acima é 


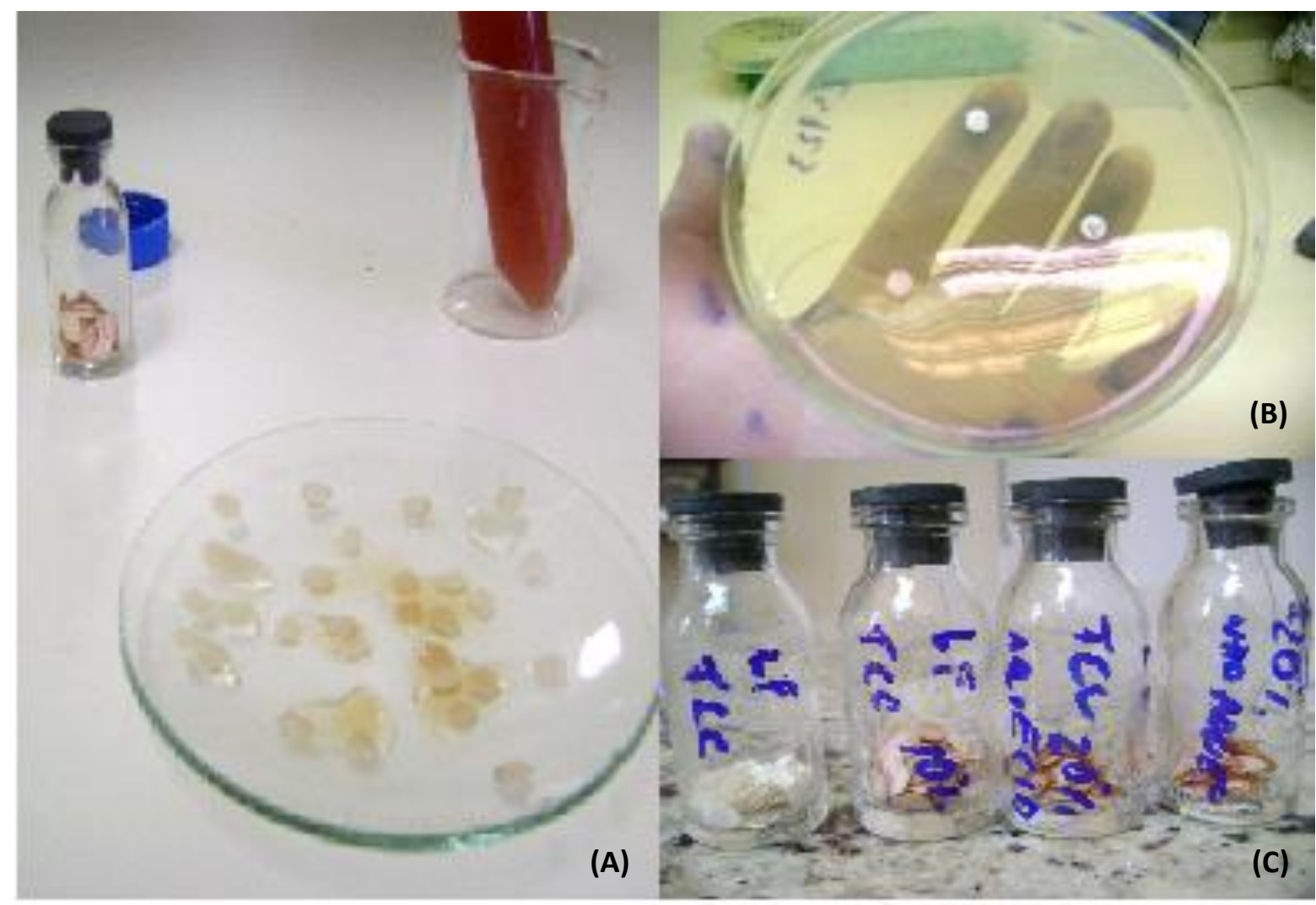

Figura 1: Confecção dos discos de antibiograma com extrato de Byrsonima crassifólia (A). Placa de Agar Muller Hilton com controle positivo (antibiótico), negativo (disco embebido com água) e teste (extratos ) (B) e Frascos contendo discos de extratos de B. crassifólia nas concentrações testadas $(10$ e $20 \%)$ (C).

Figure 1: Confection of antibiogram discs with Byrsonima extract crassifolia (A). Agar Muller Hilton plate with positive control (antibiotic), negative (embedded disk with water) and test (extracts) (B) e bottles containing extracts discs crassifolia the concentrations tested (10 and $20 \%$ ) (C).

de $16 \mathrm{~mm}$. No entanto o teste, mesmo após esta troca do controle positivo, continuou negativo em todos os retestes com o extrato de $B$. crassifolia.

Os testes realizados com Klebsiella pneumoniae submetidos a extratos na concentração de $10 \%$ não aquecido obtiveram resultados de inibição elevados. Seus halos apresentaram uma média de 8,6 $\mathrm{mm}$ (Tabela 2), sendo que seu menor halo foi de $7 \mathrm{~mm}$ e o maior de $13 \mathrm{~mm}$. Todos os controles, negativos e positivos, foram concretos e reais sem seus valores, estes determinados pela nomenclatura vigente que preconiza halo de sensibilidade para Meropenen de $16 \mathrm{~mm}^{25}$

Testes para Staphylococcus aureus apresentaram uma ação inibitória reduzida para os testes com a concentração a $10 \%$, ressaltando que se utilizou extrato bruto ao invés de purificado. As médias dos halos foram de $5,2 \mathrm{~mm}$ (Tabela 2), sendo que o menor halo foi de $4 \mathrm{~mm}$ e $13 \mathrm{~mm}$ o maior. Os controles estavam nos padrões de normalidade segundo os dados fornecidos pelo NCCLS, cujo controle positivo, a penicilina, deve ser abaixo de 28 $\mathrm{mm}$.

Pseudomonas aeruginosa teve como média em seus resultados um halo de $8,2 \mathrm{~mm}$ (Tabela 2), sendo seu menor halo de $7 \mathrm{~mm}$ e seu maior de 11 $\mathrm{mm}$. O controle positivo atendeu às expectativas fornecidas pelo NCCLS, cujo o halo de sensibilidade é acima de $16 \mathrm{~mm}$.

Nos testes utilizando extrato concentrado a $10 \%$ não aquecido, demonstrou atividade antimicrobiana para as três cepas testadas (Klebsiella pnemoniae, Pseudomonas aeruginosa, 
Tabela 2. Média do tamanho do halo de crescimento das cepas de Klebsiella pneumoniae, Staphylococcus aureus e Pseudomonas aeruginosa nos diferentes tratamentos com a raiz de Byrsonima crassifolia.

Table 2. Average size of the growth halo of standard strains of Klebsiella pneumoniae, Staphylococcus aureus and Pseudomonas aeruginosa in different treatments with root Byrsonima crassifolia).

\begin{tabular}{lccc}
\hline \multicolumn{1}{c}{ Tratamentos } & Kleibsiella pneumoniae & Staphylococcus aureus & Pseudomonas aeruginosa \\
\hline Extrato a 10\% $(\mathrm{mm})$ & $8,6 \mathrm{a}$ & $5,2 \mathrm{~b}$ & $8,2 \mathrm{a}$ \\
Extrato a 20\% aquecido $(\mathrm{mm})$ & $3,8 \mathrm{a}$ & $12,0 \mathrm{a}$ & $4,8 \mathrm{a}$ \\
Extrato a 20\% não aquecido $(\mathrm{mm})$ & $5,7 \mathrm{a}$ & $12,4 \mathrm{a}$ & $6,7 \mathrm{a}$ \\
\hline CV & $38,16 \%$ & $18,60 \%$ & $34,80 \%$ \\
\hline
\end{tabular}

*Médias seguidas pela mesma letra na coluna não se diferem estatisticamente entre si, pelo teste de Tukey à $5 \%$ de probabilidade. Os dados foram transformados para $\mathrm{V} x+1$.

*Averages followed by the same letter in the column do not differ statistically by Tukey test at $5 \%$ probability. The data were transformed to $v x+1$.

Staphylococcus aureus) e uma cepa negativada (Escherichia coli) com o extrato nessa concentração, houve o intuito de concentrar este extrato de $10 \%$ por aquecimento a 50 ㅇ $\mathrm{C}$ e outra alíquota do extrato concentrada sem aquecimento para concentração de $20 \%$. Com este procedimento houve diferença quanto ao processo de inibição e resultando em redução ou aumento dos halos.

Com as cepas de Klebsiella pneumoniae, quando com extrato a $20 \%$ aquecido, observou-se um efeito inibitório reduzido em comparação ao extrato não aquecido a $10 \%$, embora mesmo assim tenha havido ação antibacteriana. A média dos halos de inibição reduziu-se para 3,8 mm (Tabela 2); seus dados reais dos testes obtiveram como seu menor halo de inibição $3 \mathrm{~mm}$ e maior halo de 10 $\mathrm{mm}$. Contudo, além da redução dos halos de inibição houve repetições nas quais o potencial inibitório foi nulo, ou seja, negativo. Com o extrato a $20 \%$ sem o processo de aquecimento a 50 으, os halos de inibição aumentaram em relação ao teste no qual o extrato foi submetido a aquecimento. Os halos de inibição aumentaram, apresentando média de $5,7 \mathrm{~mm}$ (Tabela 2), sendo seus resultados extremos de 8 e $15 \mathrm{~mm}$.

Ocorreu o inverso com o antibiograma para as cepas de Staphylococcus aureus, cujos halos apresentaram uma inibição bacteriana significante. Sua média foi de $12,0 \mathrm{~mm}$ (Tabela 2) e seu maior e menor halo foram de 15 e $6 \mathrm{~mm}$, respectivamente, quando submetidas ao extrato $20 \%$ aquecido. Com o extrato concentrado a $20 \%$ não aquecido, os resultados mostraram um potencial antimicrobiano maior que os do extrato não aquecido a $10 \%$, e resultados maiores que os do extrato a $20 \%$ aquecido, gerando uma média de $12,4 \mathrm{~mm}$.

Os testes com Pseudomonas aeruginosa, extratos a 10 e $20 \%$ não aquecidos, resultaram em uma redução na ação inibitória. Isso ocorreu pelo fato de haver uma gama relevante de repetições negativadas. A média do halo para as repetições do extrato a $20 \%$ aquecido foi de $4,8 \mathrm{~mm}$ (Tabela 2 ), sendo que seus halos maior e menor foram de $12 \mathrm{e}$ $7 \mathrm{~mm}$.

Com o extrato a $20 \%$ não aquecido, os resultados foram mais compensatórios que os apresentados pelo teste com a mesma concentração, porém aquecida. Embora o extrato citado tenha passado por etapa de aquecimento, a média do teste com extrato a $20 \%$ sem aquecimento foi $6,7 \mathrm{~mm}$ (Tabela 2), sendo que seus valores extremos nas repetições do teste foram 11 e $5 \mathrm{~mm}$.

Os testes em cepas de Escherichia coli com todos os extratos e concentrações não apresentaram inibição bacteriana, representando assim resistência aos princípios ativos contidos nas raízes de $B$. crassifolia, quanto aos antibióticos preconizados pelo $\mathrm{NCCLS}^{25}$, estes utilizados como controle positivo. A primeira a ser testada como controle positivo foi a ampicilina com ácido clavulânico. As cepas de E. coli apresentaram resistência ao antimicrobiano, o que fez necessário o uso da segunda droga de escolha, o meropenen, que respondeu positivamente à atividade antimicrobiana, sendo assim utilizado como controle positivo.

Os resultados sugerem que existam mais de um componente com ações antimicrobianas presentes nas raízes de Byrsonima crassifolia. 0 
extrato considerado bruto com presença de vários outros elementos em sua composição, ao ser aquecido, pode ter ocasionado a eliminação de alguns interferentes contidos no seu meio aquoso, acarretando valores diferenciados para os três tratamentos nas bactérias em teste.

Processos como o de aquecimento podem desnaturar estruturas funcionais, que possuem potenciais antimicrobianos, antifúngicos ou apenas estruturais de biomoléculas ativas; ou essas moléculas em foco podem ser termorresitentes. Assim, com a desnaturação e degradação das demais substâncias contidas no meio, pode se potencializar o efeito das substâncias resistentes, como pode ter ocorrido com o extrato de $B$. crassifolia. ${ }^{26,27}$ Quando os extratos foram submetidos ao processo de aquecimento a $50^{\circ} \mathrm{C}$, o potencial antimicrobiano manteve-se em todas, com exceção da cepa de E. coli.

De acordo com as cepas e a condição de produção do extrato (aquecido ou não) houve resultados divergentes. Nas cepas de Pseudomonas aeruginosa e Klebsiella pneumoniae a temperatura reduziu a ação antimicrobiana do extrato para quase $50 \%$ da atividade, quando comparado aos testes nos quais o extrato não sofreu aquecimento. O contrário ocorreu com a cepa de Staphylococcus aureus, em que a concentração aumentada para o dobro da concentração inicial (10\%) dobrou a atividade antimicrobiana, isso tanto com extratos obtidos por aquecimento a $50 \circ \mathrm{C}$ quanto com desidratação a temperatura ambiente. Portanto, pode-se supor que existem duas classes de substâncias no extrato das raízes de $B$. crassifolia, quando se refere a temperatura, substâncias termossensíveis a 50 으 e outras termorresitentes. Por essa peculiaridade, manteve-se atividade antimicrobiana nos extratos em ambos os processos de obtenção destes.

Observou-se também que as raízes quando estavam passando pela etapa de desidratação na estufa de secagem liberaram duas secreções de cores distintas, uma cor amarelo-esverdeada e outra com coloração vermelha vinho, podendo tratar-se de dois antioxidantes: a quercetina e antocianina. Pesquisas recentes sobre a família Malpighiaceae relatam alta concentração de flavonoides naturais nestas plantas. ${ }^{15,28}$

Pesquisas com antocianinas extraídas do açaí demonstraram que o processo de degradação iniciase aos $25 \circ \mathrm{C}$ em proporção lenta e aumenta conforme a temperatura. Assim determinou-se que em temperaturas acima de $50^{\circ} \mathrm{C}$ a degradação é oito vezes mais rápida que em temperatura de $25 \circ \mathrm{C}$, e que para uma degradação total deve-se ultrapassar ou estar próximo a $90{ }^{\circ} \mathrm{C} .{ }^{29}$ Outro caso aplica-se a quercetina, que contém uma estabilidade muito elevada quando exposta a altas temperaturas comparando com outras antocianinas, como a catequina, por exemplo. ${ }^{30,31}$

\section{CONCLUSÃO}

Os extratos aquosos de raízes de Byrsonima crassifolia têm ação antimicrobiana sobre as bactérias utilizadas, exceto para Escherichia coli, evidenciando, assim, que o seu uso na medicina popular contra algumas infecções acometidas por Klebsiella pneumoniae, Staphylococcus aureus e Pseudomonas aeruginosa tem ação antimicrobiana demonstrada por este trabalho. Entretanto, mais estudos devem ser realizados para investigação da toxicidade dessa planta quanto ao uso de doses mais elevadas e por períodos maiores de tempo.

\section{CONTIBUIÇÃO DOS AUTORES}

\section{Desenvolvimento e condução do experimento; Elaboração do artigo científico.}

Luís Fernando Albarello Gellen

Edgard Henrique Costa Silva

2. AKELERE, O. Importance of Medicinal Plants: WHO'S Programme in Natural Resources and Human Heallth. Elsevier Amsterdam, Netherlands, p. 63-77, 1992.

3. AMAL, A.; ASHRAF, A.; HOSSAM, E.S. Chemical compositions and antioxi-dant/antimicrobial activities of kaff maryam (Anastatica hierochuntica) and doum palm (Hyphaene thebaica) cultivated in Egypt. Journal 
Biyoloji Bilimleri Arastirma Dergisi, v.2, n.2, p.71-79, 2009.

4. MENDONÇA, R. C.; FELFILI, J. M.; WALTER, B. M. T.; SILVA, M. C.; REZENDE, A. R.; FILGUIERAS, T. S.; NOGUEIRA, P. E. Flora vascular do Cerrado. In: SANO, S. M, ALMEIDA, S. P., (Eds.). Cerrado ambiente e flora. Brasília: EMBRAPA, p.286-556, 1998.

5. OMS. The importance of Pharmacovigilance : safety monitoring of medicinal products. Genebra : OMS, 2000.

6. FERRONATO, R., MARCHESAN E.D.; PEZENTI, E.; BEDNARSKI, F.; ONOFRE, S.B. Atividade antimicrobiana de óleos essenciais produzidos por Baccharis Dracunculifolia DC. E Baccharis uncinella D.C. (Asteraceae). Revista Brasileira de Farmacognosia, v.17, n.2, p.30-224, 2007. Crossref

7. RODRIGUES, P.A. Atividade gastroprotetora e antioxidante de extratos e constituintes químicos de Byrsonima Seicea DC. E Plectranthus Grandis Cramer (Willensem). 147f. Tese (Doutorado em ciências veterinárias) da Universidade Estadual do Ceará (UEC), Fortaleza, Ceará, 2008.

8. VARGAS, A.C.; LOGUERCIO, A.P.; WITT, N.M.; COSTA, M.M.; SILVA, M.S.; VIANA, L.R. Atividade antimicrobiana "in vitro" de extrato alcóolico de própolis. Ciência Rural, v.34, n.1, p.159-163, 2004. Crossref

9. GOLAN, D.E., TASHJIAN, A.H., ARMSTRONG, E.J., ARMSTRONG, A.W. Princípios de Farmacologia: A Base Fisiopatológica da Farmacoterapia. 2ed. Rio de Janeiro: Guanabara Koogan, p.662-683, 2009.

10. WILLIANS, D.A.; LEMKE, T.L. Foye's Principles of Medicinal Chemistry. $5^{\circ}$ ed., Philadelphia, p.1114, 2002.

11. ARAÚJO, A.C.; SILVA, J.P.; CUNHA, J.L.X.L; ARAÚJO, J.L.O. Caracterização socio-econômico-cultural de raizeiros e procedimentos pós-colheita de plantas medicinais comercializadas em Maceió, AL. Revista Brasileira Plantas Medicinais v.11, n.1, p.81-91, 2009. $\checkmark$ Crossref

12. SILVA, D.S; TAKATSUKA, F.S.; ROCHA,M.R.; CUNHA,G.D.C. Efeito do extrato de sucupira (Pterodon emarginatus Vog.) sobre o desenvolvimento de fungos e bactérias fitopatogênicos. Revista Agropecuária Tropical, v.35, n.2,p.109-115, 2005.
13. PIMENTEL, F.D.O., Atividade antioxidante de Byrsonima crassa Nied. e Byrsonima fagifolia Nied. em modelos de indução de úlcera gástrica. $111 \mathrm{f}$. Dissertação (Mestrado em Farmacologia) pela Universidade de Campinas, UNICAMP. Campinas, São Paulo, 2006.

14. MORENO-SALAZAR, S.F.; ROBLES-ZEPEDA, R.E.; JOHNSON, D.E. Plant folk medicines for gastrointestinal disorders among the main tribes of Sonora, Mexico. Journal Fitoterapia, v.79, n.2, p.132-141, 2008. $\checkmark$ Crossref

15 FIGUEIREDO, M.E.; MICHELIN, D.C.; SANNOMIYA, M.; SANTOS, L.C.; ALMEIDA,L.F.R; BRITO, A.R.M.S; SALGADO, H.R.N.; VILEGAS, W. Avaliação química e da atividade antidiarréica das folhas de Byrsonima cinera DC. (Malpighiaceae). Brazilian Journal of Pharmaceutical Sciences, v.41, n.1, 2005. Crossref

16. AGRA, M.F; FREITAS, P.F.; BARBOSA-FILHO, J.M. Synopsis of the plants known as medicinal and poisonous in Northeast of Brazil. Revista Brasileira de Farmacognosia, v.17, n.1, p.114-140, 2007. Crossref

17. CARDOSO, C.R.P. Atividade mutagênica e ativadora da resposta imune celular induzidas por Byrsinima crassa Niedenzu e Byrsonima intermédia A.Juss. $100 f$. Tese (Doutorado em Biociências e Biotecnologia Aplicadas à Farmácia) pela UNESP, Araraquara, São Paulo, 2006.

18. SAÚDE-GUIMARÃES, D.A; FARIA, A.R. Substâncias da natureza com atividade anti-Trypanosoma cruzi. Revista Brasileira de Farmacognosia, v.17, n.3, p.455-465, 2007. Crossref

19. MARINHO, R.O.S. Estudo Fitoquímico Da Espécie Byrsonima Sericea e Sua Aplicação em Dermatocosmética. 100f. Dissertação (Mestrado em Ciências Farmaceuticas) pela Universidade Federal do Rio de Janeiro, UFRJ, Rio de Janeiro, Rio de Janeiro, 2008.

20. SIMÕES, C. M. O.; SCHENKEL, E. P.; GOSMANN, G.; et al, Farmacognosia: da Planta ao medicamento, Porto Alegre/Florianópolis Ed. Da UFSC, 1999; p.789-840.

21. LENNETE, EDWIN H. ET AL. Manual de Microbiologia Clínica. Editora Panamerica, Buenos Aires, 1987, $4^{\text {a }}$ edição, p.897 -898.

22. PAREKH J., CHANDA S.V. In vitro antimicrobial activity and phytochemical analysis of some Indian 
medicinal plants. Turk Journal Biology, v.31, n.8, p.5358, 2007. Crossref

23. SANTOS S.C.; FERREIRA, F.S.; ROSSI-ALVA, J.C, FERNANDEZ, L.G. Atividade antimicrobiana in vitro do extrato de Abarema cochliocarpos (Gomes) Barneby \& Grimes. Revista Brasileira de Farmacognosia, v.17, n.2, p.9-215, 2007. Crossref

24. BARBOSA, J.C.; MALDONADO JÚNIOR, W. Experimentação Agronômica \& AgroEstat - Sistema para Análises Estatísticas de Ensaios Agronômicos. Versão 1.0. Jaboticabal: UNESP, 2015.

25. NCCLS. Performance Standards for Antimicrobial Disk Susceptibility Tests; Approved Standard-Eighth Edition. NCCLS document M2-A8 (ISBN 1-56238-485-6). NCCLS, 940 West Valley Road, Suite 1400, Wayne, Pennsylvania 19087-1898 USA, 2003.

26. BIANCHINI, L.; BENEDO, I.P.;Efeito Antibiótico do Própolis Sobre Bactéria Fitopatogênicas. Sciencia e agricultura, v. 55, n.1, 1998. Crossref

27. FLAMBÓ, D.F.A.L.P. Atividades Biológicas dos Flavonoides: Atividade Antimicrobiana. 43f. Dissertação (Mestrado em Ciências Farmacêuticas) pela
Universidade Federal do Rio Grande do Sul, UFRS, Porto Alegre, Rio Grande do Sul, 2013.

28. FIGUEREDO. M.E.; MICHELIN. D.C.; SANNOMIYA, M.; SILVA, M.A.; SANTOS, L. C.; ALMEIDA, L.F.; SOUZA BRITO, A.R.M. Antimicrobial activity of Byrsonima species (Malpighiaceae) Revista Brasileira de Farmacognosia, v. 18, sup., p.690-695, 2008. Crossref

29. ALBARICI,T.R.;VALETA, A.D.C.; PESSOA, J.D.C. Efeito da Temperatura nas Antocianinas do Açaí. EMBRAPA Instrumentalização Agropecuaria, p.1-3, Ed.EMBRAPA, São Carlos-SP, 2007. Disponível em: <http://www.cnpdia.embrapa.br/publicacoes/CT86 20 07.pdf>.

30. FALCÃO, L.D.; BARROS, D.M.; GAUCHE, C.; LUIZ, M.T.B. Copigmentação Intra e Intermolecular de Antocianinas: uma revisão. Boletim do Centro de Pesquisas de Processamento de Alimento (CEPPA), v.21, n.2, p.351-366, 2003.

31. WANG, D.; WANG, L.; ZHU, F.; ZHU, J.; CHEN, X.D.; ZOU, L.; SAITO, M.; LI, L. In vitro and in vivo studies on the antioxidant activities of the aqueous extracts of Douchi (a traditional Chinese salt-fermented soybean food). Food Chemistry, v.107, p.1421-1428, 2008. Crossref 